\title{
CERAMIC MEMBRANES FOR HYDROGEN PRODUCTION FROM COAL
}

\author{
Annual Technical Report \\ September 1, 2001-August 31, 2002
}

George R. Gavalas

March 18, 2003

DE-FG26-00NT40817

California Institute of Technology

1200 E. California Blvd.

Pasadena, CA 91125 


\section{DISCLAIMER}

This report was prepared as an account of work sponsored by an agency of the United States Government. Neither the United States Government nor any Agency thereof, nor any of their employees, makes any warranty, express or implied, or assumes any legal liability or responsibility for the accuracy, completeness, or usefulness of any information, apparatus, product, or process disclosed, or represents that its use would not infringe privately owned rights. Reference herein to any specific commercial product, process, or service by trade name, trademark, manufacturer, or otherwise does not necessarily constitute or imply its endorsement, recommendation, or favoring by the United States Government or any agency thereof. The views and opinions of authors expressed herein do not necessarily state or reflect those of the United States Government or any agency thereof. 


\begin{abstract}
The objective of this project is to develop ceramic membranes for hydrogen separation from fuel gas or synthesis gas at temperatures $400-500^{\circ} \mathrm{C}$. The membrane chosen for this purpose consists of a dense silica layer coated on a porous support by chemical vapor depositrion (CVD). The support used during the reporting period was zeolite silicalite grown on macroporous alumina tubes. Chemical vapor deposition was carried out using alternating exposure of the support to silicon tetrachloride $\left(\mathrm{SiCl}_{4}\right)$ and water vapor at $400-500^{\circ} \mathrm{C}$. Under these conditions it takes about twenty-five reaction cycles to narrow down the pores of the zeolite support sufficiently for separation of hydrogen from other gases. The membranes were characterized by gas adsorption for pore size distribution, scanning electron microscopy, and EDAX for elemental composition. The permeance of $\mathrm{H}_{2}, \mathrm{~N}_{2}, \mathrm{CO}_{2}, \mathrm{n}-\mathrm{C}_{4} \mathrm{H}_{10}$, and $\mathrm{i}-\mathrm{C}_{4} \mathrm{H}_{10}$ was measured in the temperature range $100-250^{\circ} \mathrm{C}$. At $150^{\circ} \mathrm{C}$, the $\mathrm{H}_{2}: \mathrm{N}_{2}$ permeance ratio was in the range 100 200 at a hydrogen permeance of $5-10 \times 10^{-8} \mathrm{~mol} / \mathrm{m}^{2}-\mathrm{s}-\mathrm{Pa}$.
\end{abstract}

\title{
INTRODUCTION
}

The present project is devoted to developing CVD silica membranes supported on zeolite silicalite grown on $\alpha-\mathrm{Al}_{2} \mathrm{O}_{3}$ tubes of mean pore size $1 \mu \mathrm{m}$ and wall thickness 0.6 $\mathrm{mm}$. The previous annual report described the preparation, characterization, and permeation properties of the composite silicalite/alumina support. The present report describes the silica membrane preparation by chemical vapor deposition (CVD) using silicon tetrachloride hydrolysis at temperatures $400-600^{\circ} \mathrm{C}$. In previous research in our laboratory, this CVD was carried out on porous glass tubes (Vycor glass) by a series of alternating (non-overlapping) exposure to silicon tetrachloride and water vapor. The generally accepted reaction mechanism for this process is as follows:

Reaction of surface with $\mathrm{SiCl}_{4}$ (silylation)

surface-OH $+\mathrm{SiCl}_{4}=$ surface-O- $\mathrm{SiCl}_{3}$

reaction with $\mathrm{H}_{2} \mathrm{O}$ (hydrolysis) 
surface-O- $\mathrm{SiCl}_{3}+\mathrm{H}_{2} \mathrm{O}=$ surface-O- $\mathrm{SiCl}_{2} \mathrm{OH}+\mathrm{HCl}$

surface-O- $\mathrm{SiCl}_{2} \mathrm{OH}+\mathrm{H}_{2} \mathrm{O}=$ surface-O-SiCl$(\mathrm{OH})_{2}$

surface-O-SiCl(OH) $)_{2}+\mathrm{H}_{2} \mathrm{O}=$ surface- $\mathrm{OH}+\mathrm{HCl}$

Condensation (occurring throughout the cycle)

surface- $\mathrm{OH}+$ surface- $\mathrm{OH}=$ surface-O-surface $+\mathrm{H}_{2} \mathrm{O}$

surface- $\mathrm{Cl}+$ surface-OH surface-O-surface $+\mathrm{HCl}$

where in the last two reactions the $\mathrm{OH}$ and $\mathrm{Cl}$ moieties are attached on surface silicon

atoms. It is clear that once the reaction is initiated the nature of the original substrate

becomes immaterial. However, the number of silanol (Si-OH) groups on the original

surface is bound to influence the early phase of the reaction.

In the second reporting period the main objective was to use the alternating CVD reaction to coat the zeolite layer with a thin hydrogen permselective silica layer. Infiltration in the zeolitic channels was not expected to be extensive given that the molecular diameter of silicon tetrachloride $(0.55 \mathrm{~nm}$ based on covalent atomic radii) is very close to that of the MFI channels (0.51-0.55 nm).

\section{EXPERIMENTAL}

\subsection{Silica CVD on Zeolite/Alumina Tubes}

CVD was carried out using the apparatus shown in Figure 1. The membrane was held horizontally within a quartz tube connected to vacuum and to two reactant reservoirs, one containing water, the other containing the silica precursor. In most experiments, this precursor was silicon tetrachloride, $\mathrm{SiCl}_{4}(\mathrm{ST})$, in a few experiments the precursor was the dimer hexachlorodisiloxane, $\mathrm{Cl}_{3} \mathrm{SiOSiCl}_{3}$ (HDS). The quartz tube was held inside a furnace at temperatures $400-500^{\circ} \mathrm{C}$. CVD was conducted in a sequence of cycles, each of which consisted of the following 1-minute steps: 
i) with the reservoir valves closed the quartz tube is evacuated for 1 minute

ii) the valve to vacuum is shut and the valve to silicon tetrachloride reservoir is opened for 5 seconds and then shut; all valves are maintained shut for 1 minute

iii) the valve to vacuum is opened for 1 minute and then shut

iv) the valve to the water reservoir is opened for 5 seconds and then shut; all valves are maintained closed for 1 minute

The temperature of each of the two reactant reservoirs is controlled independently so that when the respective valve is shut the vapor pressure soon comes to equilibrium with the liquid. When the valve is subsequently opened up the vapor fills a larger volume with a corresponding drop in the vapor pressure. After a few seconds the valve to the reservoir is shut and the reaction proceeds in a batch fashion so that the extent of reaction in each cycle is controlled by the reservoir temperature and the reaction time, i.e., the time between opening the valve to the respective reservoir and evacuating.

Characterization. The top surface of the membranes was examined by SEM, and the elemental composition profile (silicon and aluminum) over the membrane cross section were obtained by EDAX. A major question we wished to answer was whether the silica produced by CVD was in the form of an external layer on top of the zeolite support or whether it was in the form of molecular-sized inclusions within the zeolitic channels. This problem was addressed by silicon solid state nmr on zeolite powder before and after CVD. Nitrogen adsorption and desorption isotherms were performed on membrane tubes before and after CVD to estimate the micropore volume distribution from the low relative pressure region of the isotherm using the MP method. 
Permeation Measurements. The permeance of several gases was measured every five reaction cycles by removing the tube from the CVD apparatus and placing it in a temperature-controlled permeation cell. Most measurements were conducted with single gases $\left(\mathrm{H}_{2}, \mathrm{~N}_{2}, \mathrm{CO}_{2}, \mathrm{CH}_{4}, \mathrm{n}-\mathrm{C}_{4} \mathrm{H}_{10}, \mathrm{i}-\mathrm{C}_{4} \mathrm{H}_{10}\right)$. Permeances above $0.1 \mathrm{MPU}(1 \mathrm{MPU}=$ $10^{-8} \mathrm{~mol} / \mathrm{m}^{2}$-s-Pa) were measured under continuous flow where the feed passed outside the tube at 1.5-2 bar pressure while the permeate gas was collected from the tube bore at atmospheric pressure measured using a bubble flowmeter. Permeances below $0.1 \mathrm{MPU}$ were measured using the pressure rise technique whereby the feed was passed at the outside of the tube at 1 bar pressure while, initially, the tube bore was kept under vacuum. After allowing sufficient time to reach steady permeation through the membrane, the valve to vacuum was shut and the rising pressure was measured by a sensitive capacitance gauge. The permeance was then calculated from the rate of pressure rise and the calibrated volume of the tube bore plus that of the tube connection to the pressure gauge.

\section{Results and Discussion}

Characterization. The NMR spectra of silicalite powder before and after CVD show considerable peak overlap. After CVD, the spectrum has sharply defined peaks, all of which correspond to the known spectrum of MFI. There is no peak characteristic of a new silicon species.

Nitrogen adsorption and desorption isotherms were performed on tubes before and after CVD. Figure 2 shows the micropore volume distribution calculated from the low relative pressure region of the isotherm. Although the absolute pore sizes using the MP and other methods are model-dependent and subject to considerable uncertainty, the comparison between the results before and after CVD is meaningful. The larger peaks at 
about $0.1-0.3 \mathrm{~nm}$ pore radius can be attributed to the zeolitic channels. CVD clearly shifts the peak center from around 0.23 to $0.2 \mathrm{~nm}$ and increases the total volume in this region. Before CVD, the membrane also possessed micropores with radius $0.5-0.75 \mathrm{~nm}$ attributed to grain boundaries between the crystals. CVD appears to have shifted these nonzeolitic micropores to lower radii. The size of $\mathrm{SiCl}_{4}$ sets a lower bound of about $0.25 \mathrm{~nm}$ below which no further reduction of these nonzeolitic micropores is possible.

Permeation Results. Permeation rates of single gases during CVD on one support tube tube are shown in Figures 3-5. The decline of hydrogen flux with increasing number of CVD cycles is much slower than that of other gases. Among the other gases, n-butane undergoes the sharpest decline until about cycle 15 . The permeance of isobutane declines more slowly and both butanes stop declining after about 20 cycles. These results can be interpreted in terms of the changes of transport pathways during CVD. The bulk of the transport of all gases initially takes place through the zeolitic channels as evidenced by the high initial ideal selectivity between the two butanes. The faster decline of n-butane vs. isobutane suggests that a significant fraction of the isobutane flux proceeds through nonzeolitic membrane defects. Some information about the membrane grain boundaries and other defects can be obtained by comparing the flux decline of the two butanes. Assuming that the zeolitic channels narrowed by silica CVD are inaccessible to both butanes, the fractional decline of both fluxes through the zeolitic channels must be the same. The overall decline factor in 15 cycles is about 600 for n-butane but only 25 for isobutane, implying that the bulk of the isobutane flux is through nonzeolitic pathways that are only very slowly obstructed by CVD. In fact, there is little flux change of either butane after 20 reaction cycles. The residual flux must be due to relatively large defects of size in the tens of nanometers that are only extremely slowly narrowed by CVD of 
silica. Previous work has shown that each CVD cycle adds about $0.03 \mathrm{~nm}$ of silica, therefore defects in the range of tens of nanometers would not be sealed in 25 or even 100 CVD cycles. Figure 4 gives the ideal selectivities (permeance ratios for single gases) for three gas pairs After $25 \mathrm{CVD}$ cycles, the $\mathrm{H}_{2}: \mathrm{N}_{2}$ permeance ratio has risen to about 160, while the butane ratio has dropped to approximately unity. The $\mathrm{CO}_{2}$ to $\mathrm{CH}_{4}$ ratio has risen moderately to about 15 .

Figure 5 shows the temperature dependence of the permeances of three gases vs. temperature in the range $100-250^{\circ} \mathrm{C}$. The hydrogen and nitrogen permeances increase slightly with the permeance ratio declining from 140 at $100^{\circ} \mathrm{C}$ to 110 at $250^{\circ} \mathrm{C}$. The carbon dioxide permeance declines slightly with increasing temperature consistent with the role of adsorption for this particular gas. Although measurements were not conducted above $250^{\circ} \mathrm{C}$, it is expected that the membrane separation selectivity will decline further with increasing temperature. Measurements with several other membranes prepared under similar conditions yielded similar results.

In an effort to verify that the change of permeation properties was due to the narrowing of the zeolitic channels rather than to the formation of an external silica layer, experiments were carried out using the "dimer" HDS instead of $\mathrm{SiCl}_{4}$. Although of similar cross section, the longer dimer was expected to penetrate the zeolitic channels more slowly. Figure 6 shows the results obtained using a longer series of cycles, the first forty employing the dimmer, the last fifteen the monomer. There is no qualitative difference from the results of Figure 3. The residual permeance of the butanes again indicates the presence of large defects that cannot be completely sealed by CVD. Penetration in the zeolitic structure is slower but eventually leads gradual reduction of the hydrogen permeance. In all cases the substrate silicalite layers had defects of tens of 
nanometer size that adversely affected selectivity. Although carrying out the CVD at higher temperatures would accelerate the reaction rate so that fewer cycles would be required, it was not applied because it was found to increase the defects in the zeolite layer.

\section{CONCLUSIONS}

(i) CVD by half reactions of silicon tetrachloride or the related dimmer and water vapor at temperatures 400 , and $450^{\circ} \mathrm{C}$ did not produce a silica layer but introduced silica species into the zeolitic channels.

(ii) The narrowing of the zeolitic channels resulted in a gradual increase of the $\mathrm{H}_{2}: \mathrm{N}_{2}$ permeance ratio at $150^{\circ} \mathrm{C}$ from about 3 before CVD to $100-200$ after 25 cycles of CVD. The $\mathrm{H}_{2}: \mathrm{CO}_{2}$ ratio was lower, about 30 . These properties are the direct consequence of the fact that separation takes place by the narrowed zeolitic channels rather than by an external silica layer.

(iii) Using silicalite membranes with fewer or smaller defects would provide higher selectivities but the useful temperature range would remain below $250^{\circ} \mathrm{C}$. 


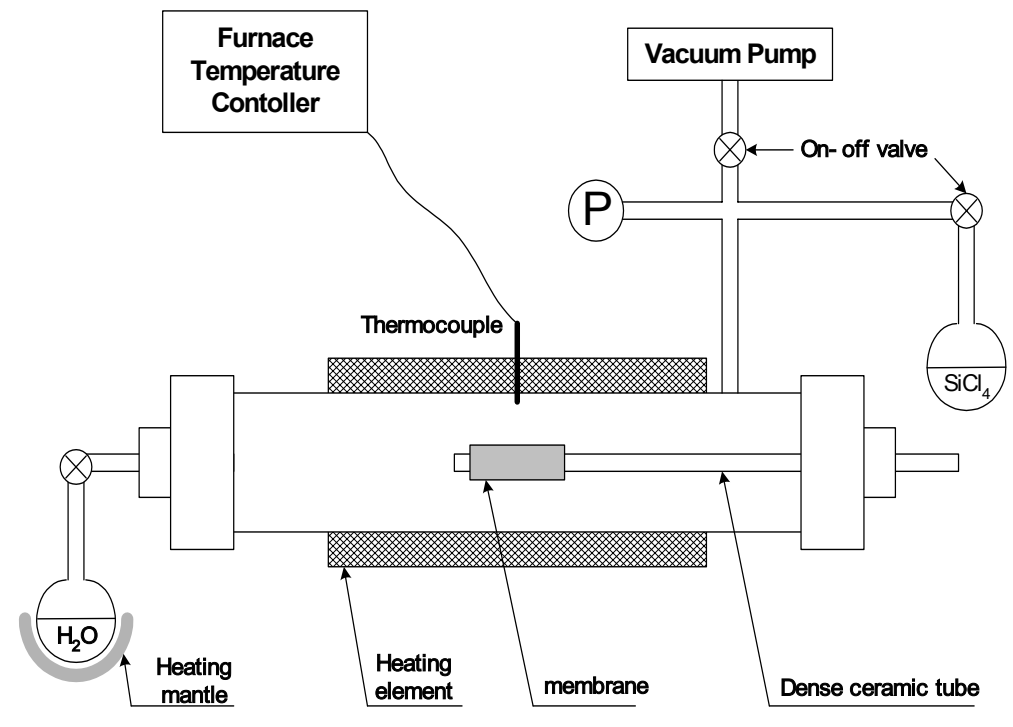

Figure 1. Apparatus for silica CVD by half reactions of $\mathrm{SiCl}_{4}$ and $\mathrm{H}_{2} \mathrm{O}$ 


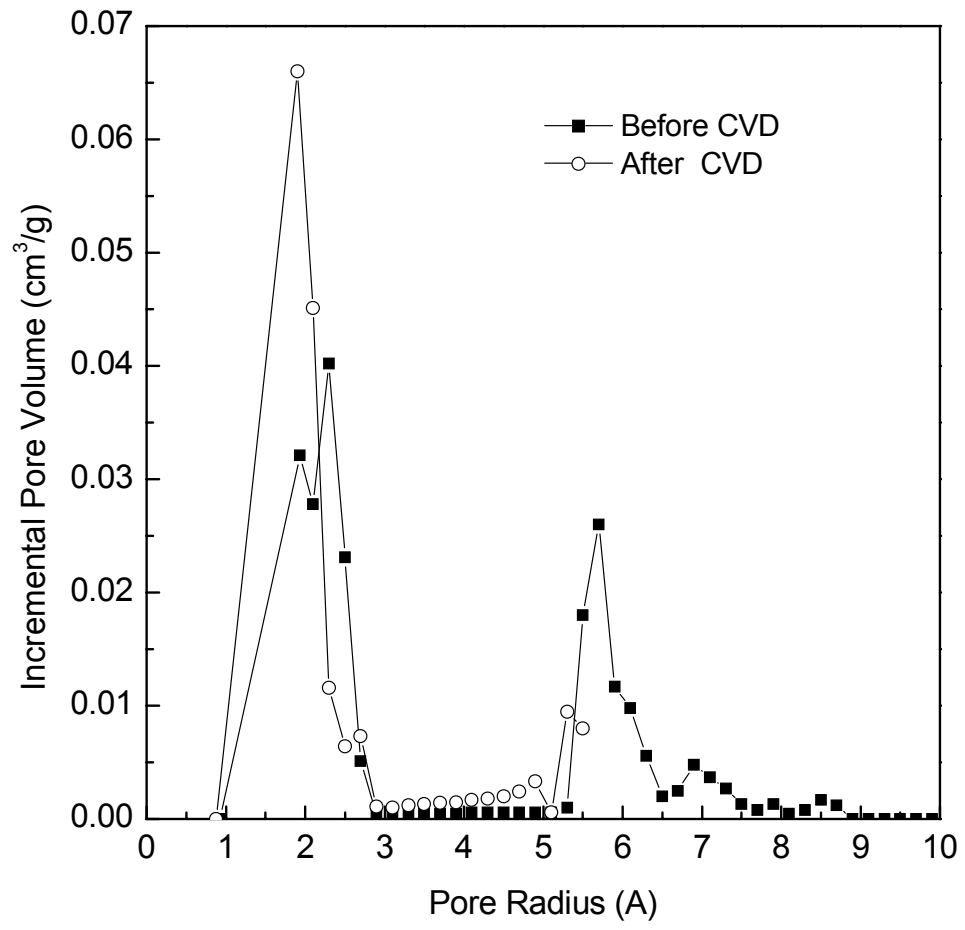

Figure 2. Pore size distribution of silicalite powder before and after CVD 


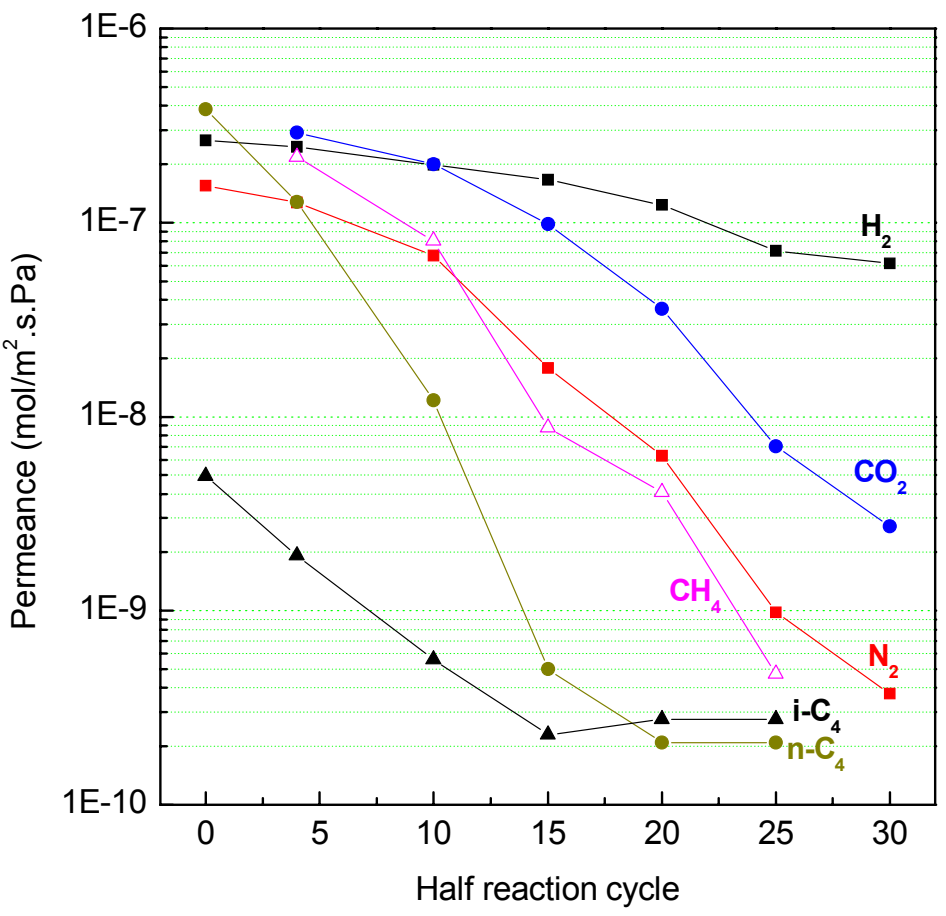

Figure 3 . Permeance of single gases at $150^{\circ} \mathrm{C}$ vs. CVD cycle at $450^{\circ} \mathrm{C}$. 


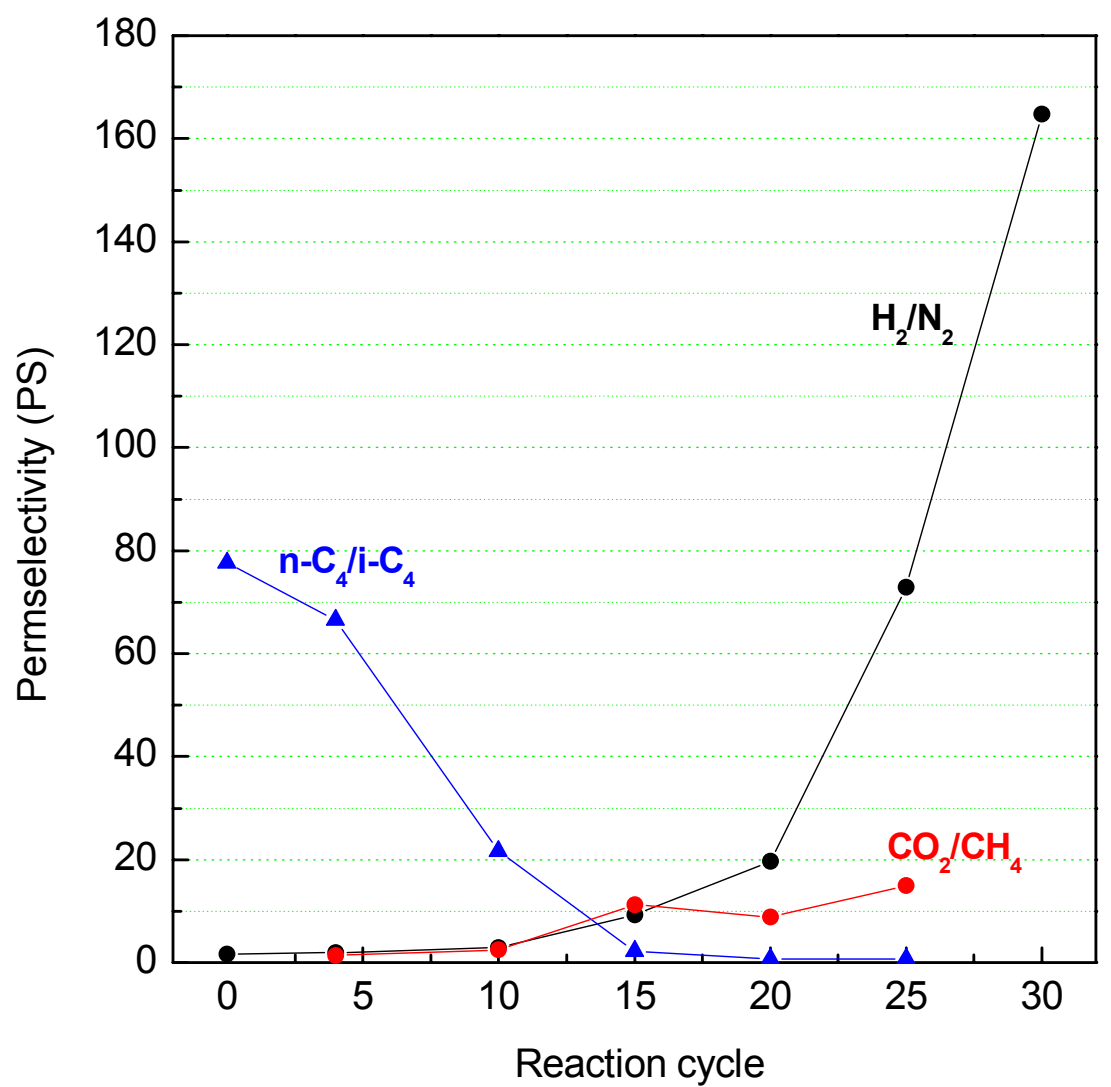

Figure4. Ideal selectivity of a membrane at $150^{\circ} \mathrm{C}$ vs.number of CVD cycles at $450^{\circ} \mathrm{C}$. 


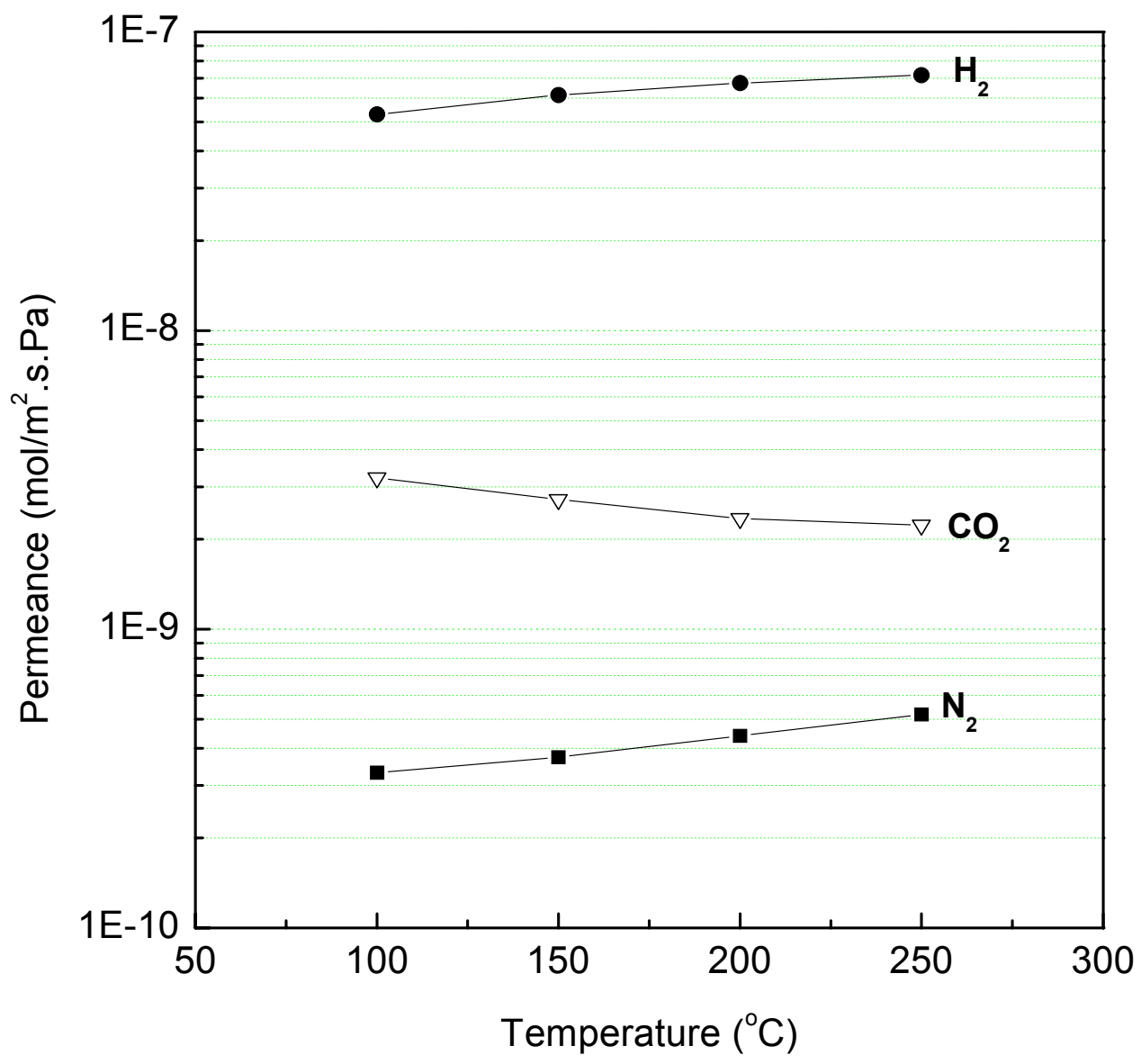

Figure 5. Temperature dependence of single gas permeances. 


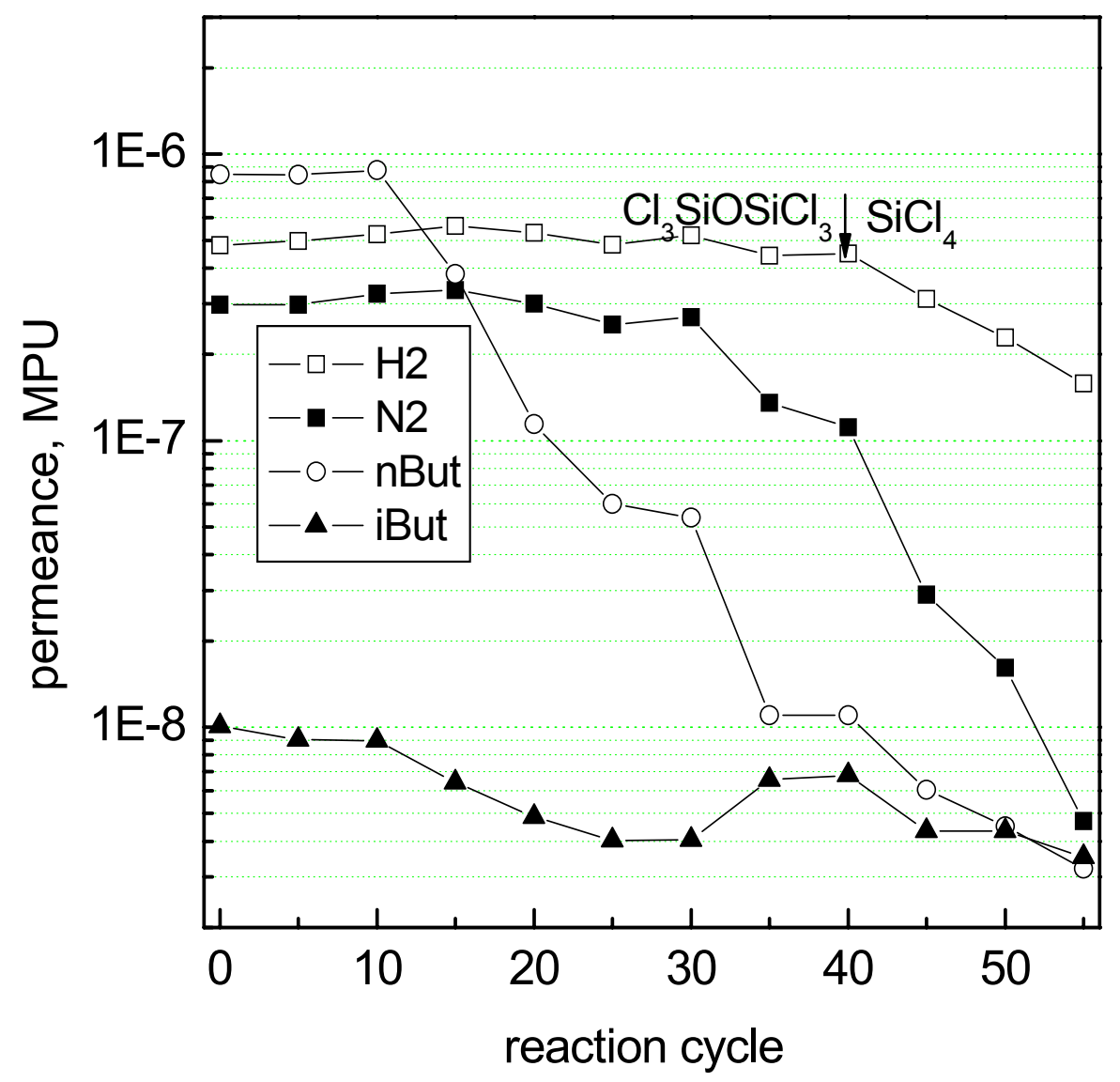

Figure 6. Permeance of several gases at $150 \mathrm{oC}$ vs. CVD cycle number at $450 \mathrm{oC}$. The dimmer HDS was used up to cycle 40 and then replaced by the monomer ST. 


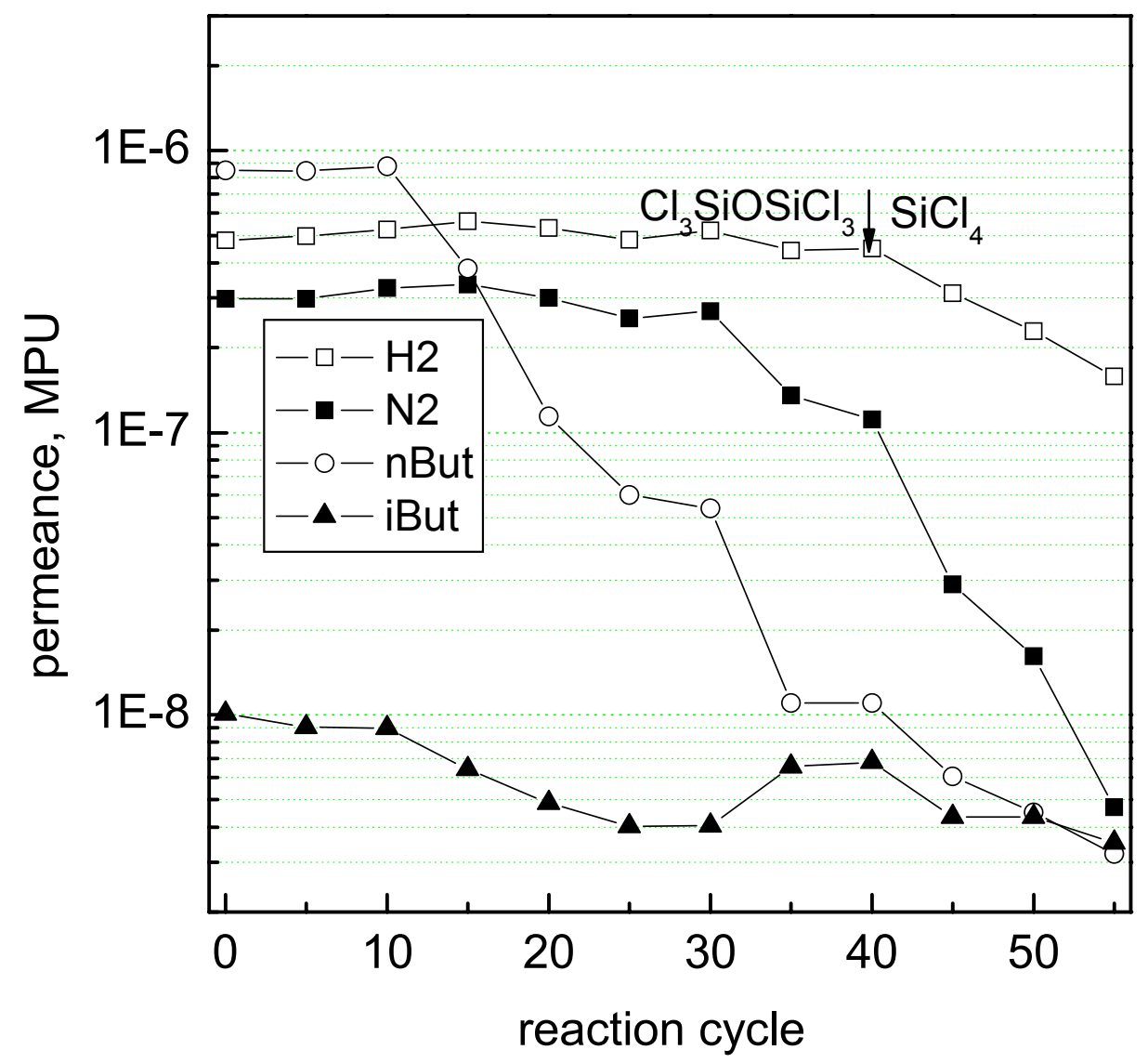

Figure 6. Permeance of several gases at $150^{\circ} \mathrm{C}$ vs. CVD cycle number at $450^{\circ} \mathrm{C}$. Cycles $1-40$ carried out with the dimer HDS, cycles above 40 with the monomer ST. 